\title{
Poisson's Ration, Deep Resistivity and Water Saturation Relationships for Shaly Sand Reservoir, SE Sirt, Murzuq and Gadames Basins, Libya (Case study)
}

\author{
Bahia M. Ben Ghawar ${ }^{1} \&$ Fathi S. Elburas ${ }^{2}$ \\ ${ }^{1}$ Faculty of Engineering, Geological Engineering Department, Tripoli, Libya \\ ${ }^{2}$ Faculty of Sciences, Geophysics Department, Tripoli, Libya \\ Correspondence: Bahia M. Ben Ghawar, Faculty of Engineering, Geological Engineering Department, Tripoli, \\ Libya. Tel: 1-613-947-3592. E-mail: gloriamuftah@yahoo.com
}

Received: June 17, 2014

Accepted: July 7, 2014

Online Published: February 7, 2015

doi:10.5539/jgg.v7n1p20

URL: http://dx.doi.org/10.5539/jgg.v7n1p20

\begin{abstract}
It is important to obtain relationships between the physical quantities, overburden and reservoir composition and fluid type. This is significant in the sense that if one property, e.g., electrical resistivity, can be more easily measured than Poisson's ratio (PR). Therefore, later parameter can be estimated and defined against resistivity log data. In fact, these relations constructed by several wells data have been taken for each studied productive reservoir from different oil fields at different sedimentary basin, in Libya. However, comparison between calculated PR, measured deep resistivity and calculated water saturation content are using to a certain extent justification of reservoir conditions (tight zone).

These cross relations throw up the increase of PR range at low values of deep resistivity values and water saturation degrees, which present like a hyperbolic curves formed a two parts. The stable trend with constant PR values in hydrocarbon and clean intervals depths within a first part, while a shaly depth intervals act as a second part of the hyperbolic shape, which shows a scatter or cluster points indicates of water intervals and not a tight zone. Therefore, estimation of PR in shaly intervals in such these reservoirs are ranging above 0.3 up to 0.4 .
\end{abstract}

Keywords: Poisson's Ratio, porosity, deep resistivity, water saturation

\section{Introduction}

Any reservoir rock has electrical property related to lithological type and characteristic. In fact, this electricity is function of many factors which one of them fluid type. Hydrocarbon and water are the main prospective fluids filled the different porosity types of reservoir rocks. However, Deep resistivity wire line log data relate to Poisson's ratio (PR) is the main task in this work for shaly sand throughout different reservoir rocks, which have different location and depositional environments. One of these studied reservoirs is gas producer. In additional, affect and distribution behavior of water saturation over these reservoirs relate also to the Poisson's ratio. Thickness of the studied reservoir ranged from 100 to 400 feet.

Benefit of these cross properties to determine variety values of geomechanical properties (PR) throughout the productive reservoir clean and/or shaly depth intervals. These depths associated with the PR changed range helping to delineate weakness depths intervals.

This work present an approach helps to understand primary geologic controls on rock mechanical properties and to translate this new insight into novel predictive tools. Therefore, using of multivariate statistics to generate lithotype-dependent empirical predictive relationships between mechanical properties and log-derived petrophysical attributes/properties. It is give an idea about strength for perforation stability, rock compressibility for reservoir simulation. Finally, test overall performance and quantify uncertainty in predictions. Therefore, this approach has provided a more predictive model to be applied in a field in one of the early investigation stage of geomechanical properties.

Ursin and Carcione (2007) relate the electrical conductivity to the P-wave velocity. Hilfan and Zuhar (2007) construct alternatively new technique by using joint two techniques which relate between velocity and conductivity. Dvorkin et. al., (2001) present an observation change of Poisson's ratio with porosity and water 
saturation in Sandstone with different degree of shale content. Dvorkin (2006) present an abnormally high PR values sometimes observed in well data in gas sand. Most theories indicate that PR in gas saturated sand lies within a zero to 0.25 ranges, with typical values about 0.15 . However, some well log measurements, especially in gas formations, persistently produce a Poisson's ratio as large as 0.3 .

The electrical properties of reservoir rocks which have a significant volume of clay have been discussed in the literature for more than three decades. It is generally accepted that clay affects the electrical conductivity which is measured in these so-called shaly sands, but a variety of opinions exist about what combination of rock and fluid parameters best characterizes the variation of the parameters best characterizes the variation of the conductivity of a shaly sand with variation of the conductivity and volume of a saturating brine (1989). Perez (2013) investigate how changes in mineralogy and porosity affect the effective elastic moduli and presents chart interpretate the rock physics trends in Poisson's ratio and Young's modulus space with constant lines of bulk modulus.

\section{Methodology}

Four wells are productive from clastic reservoir rock type, which they are located at three different sedimentary basins in Libya. Have wire-line logging data used to study variety of Poisson's ratio (PR) with the electrical property (measured deep resistivity), fluid type (hydrocarbon and/or water) and its saturation degree.

Poisson's ratio (PR) can be calculated from any other pair, such as bulk and shear moduli or the two Lame's constants. It can also be calculated from the P- and S-wave elastic-wave velocities, which are routinely measured in the laboratory and/or well. One may find it is more convenient to use PR rather than the velocity ratio $(\mathrm{Vp} / \mathrm{Vs})$ simply because the former is contained between zero and 0.5 while the latter may span the range between the square root of 2 and infinity.

Poisson's ratio is the ratio of expansion in one direction of a rock caused by a contraction at right angles. The Poisson's ratio of most materials is between 0.0 and 0.5. If the material is showing almost no Poisson contraction as a response to extension, then the Poisson's ratio is 0 . On the other hand, a perfectly in compressible material deformed elastically at small strains would have a Poisson's ratio of 0.5. Rocks are subject to Poisson's effect under stress and strain. For instance, excessive erosion or sedimentation in the overburden can either create or remove large vertical stresses on a particular rock layer, under which it will deform in the horizontal direction as a result of Poisson's effect. This change in strain in the horizontal direction can affect formation of joints or local stresses in the rock.

Determination of Poisson's ratio (PR) is very useful when calculating rock mechanical properties such as compressive strength, angle of internal friction, and cohesive shear strength. Poisson's ratio is also useful for modeling seismic responses, borehole stresses, and acoustic responses of the selected formation(s). Poisson's ratio is dependent on pore fluid characteristics and on the shaliness of the selected formation(s). This parameter is computed by the following formula (1), which depend on volume of shale (Crain , 2000).

$$
\mathrm{PR}=0.125 * \mathrm{Vsh}+0.27
$$

Calculation of the gamma ray index is the first step needed to determine the volume of shale from gamma ray log. Gamma ray log is often the best shale indicator available, which is recored over the drilled reservoir intervals, fast and very simple method, and generally the most reliable. The gamma ray log has several nonlinear empirical responses as well a linear responses. The non linear responses are based on geographic area or formation age. All non linear relationships are more optimistic that is they produce a shale volume value lower than that from the linear equation (Asquith and Krygowski, 2004). A main step for the Shaly sands reservoir evaluation is to determine the effects of shale upon porosity, permeability and fluid saturations. The multiple measurements of porosity logs (Neutron and Density) can frequently be used together to determine porosity, because the $\emptyset_{\text {nd }}$ generally provides the best sensitivity to lithology, porosity, hydrocarbons, and shaliness.

Electrical resistivity is the ability of a substance to impede the flow of an electrical current. This is a very important rock property in formation evaluation as it helps to differentiate between formations filled with salty waters (good conductors of electricity) and those filled with hydrocarbons (poor conductors of electricity). Also, this measured of rock proprty is affected by pore space and also matrix content.

Archie equation is not an adequate for water saturation determination in shaly sand, due to overestimates of saturation degrees. Simandoux equation (2) reduces to the Archie equation when volume of shale equal zero. When low resistivity shale is present, the Simandoux equation accounts for the resistivity of the shale and generates a more accurate water saturation (Crain and Holgate, 2014). The Simandoux equation works well for most situations and the most common when shale unknown exactly distriution, therefore, it used in the studied 
reservoirs.

$$
S_{w}=\frac{a \mathrm{R}_{\mathrm{w}}}{2 \varphi^{m}}\left[-\frac{V_{s h}}{R_{s h}}+\left(\left(\frac{V_{s h}}{R_{s h}}\right)^{2}+\frac{4 \varphi^{m}}{\mathrm{a} \mathrm{\textrm {R } _ { \mathrm { w } }} \mathrm{R}_{\mathrm{t}}}\right)^{0.5}\right]
$$

Where:

a = tortuosity exponent.

$\mathrm{m}=$ cementation exponent.

$\varnothing=$ porosity $\left(\varnothing_{\text {nd }}\right.$, fr. $)$.

$\mathrm{R}_{\mathrm{t}}=$ deep resistivity $\log$ reading $(\Omega . \mathrm{m})$.

$\mathrm{R}_{\mathrm{sh}}=$ resistivity of the shale $(\Omega . \mathrm{m})$.

$\mathrm{V}_{\text {sh }}=$ shale content (fr.).

$\mathrm{R}_{\mathrm{w}}=$ water resistivity at formation temperature $(\Omega . \mathrm{m})$.

Estimation of volume of shale (or clay content, Vsh) in these reservoirs was computed by using gamma ray log (GR) data as prevouse mentioned for older rock formula. Usually gamma ray do not gives an idea about the shale distribution cross the studied reservoir. Therefore, cutoff values of the Vsh for each well take separately and most value was $20 \%$. A conditional filter $(20 \%>\mathrm{Vsh}>20 \%)$ has been applied to identify clean sand and shale intervals.

\section{Results and Discusion}

Elastic property (PR) changes with measured deep resistivity through the productive reservoir depths as Hyperbola relationship. Figures 1, 2, 3 and 4, illustrate with discrimination between clean and shaly intervals in both oil and gas productive wells. Through this section pattern between clean and shaly depths clearly discriminate when stable PR values (about 0.27) against resistivity changes in clean depths (Vsh $<20 \%$ ) was function of porosity content. While change in PR values excess (about 0.35 ) in shaly depths.

The PR changing values along reservoir shaly depths are important to define and determine a weakness for stresses depths. In other meaning, a little change of this elastic rock parameter in clean intervals occurred only at low measured deep resistivity $(10-20 \mathrm{Ohm} . \mathrm{m})$ as present in the following Figures.

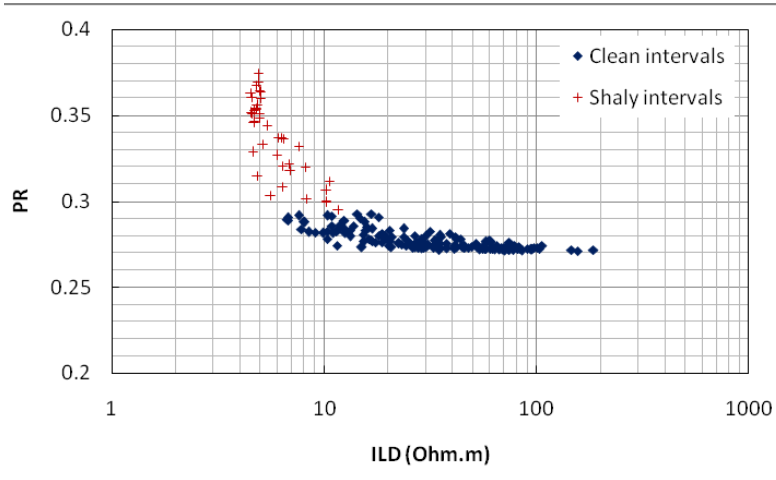

Figure 1. Deep Resistivity versus Poisson's Ratio of Studied Reservoir, SE Sirt Basin, Libya

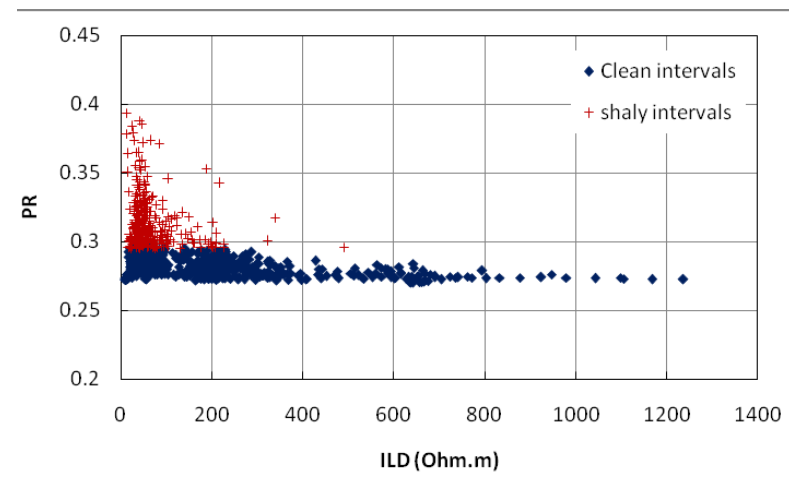

Figure 2. Resistivity versus poisson's ratio of stuudied reservoir, Murzuq Basin, Libya 


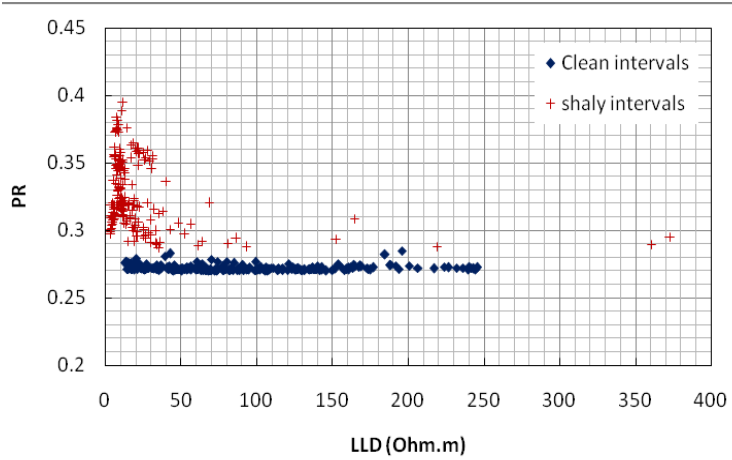

Figure 3. Resistivity versus poisson's ratio of reservoir studied, Ghadamas Basin, Libya

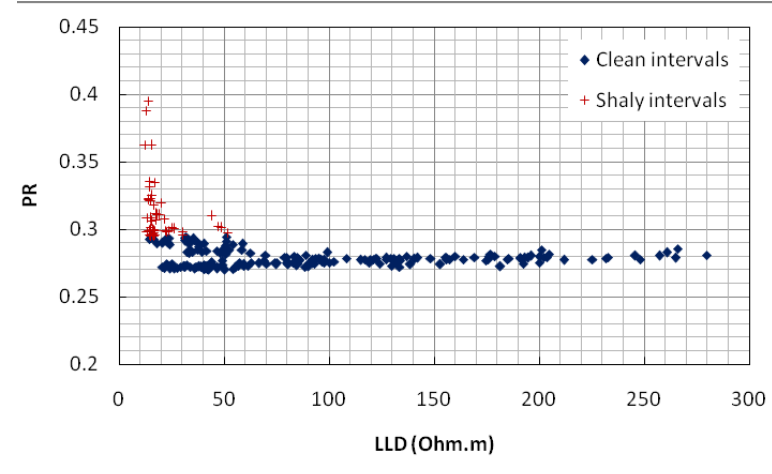

Figure 4. Resistivity versus poisson's ratio of studied reservoir (Gas well), Ghadamas Basin, Libya

The fluid effect depends on its degree of saturation and geometry of the pores. Most water is present in upper part of any reservoir is interstitial water associated with the hydrocarbon or as a main part of chemical structure of the rock matrix (clay minerals). This amount of water is an increase with depth. Also, this water amounts related to the shale content and its type in such like these different studied reservoirs. However, relation of water saturation and geoelastic property (PR) is essential to show a percentage of water saturation which causes the weak depths in the reservoir rock. Generally Figures (5,6 and 7) show clean intervals have a stable trend; whereas shaly intervals have a scattered with high values of PR even this intervals located at production depths.

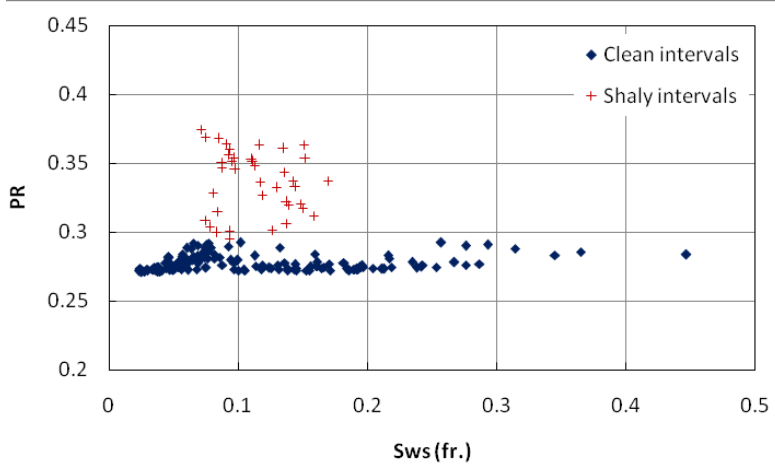

Figure 5. Water saturation versus Poisson's ration of studied reservoir, SE Sirt Basin

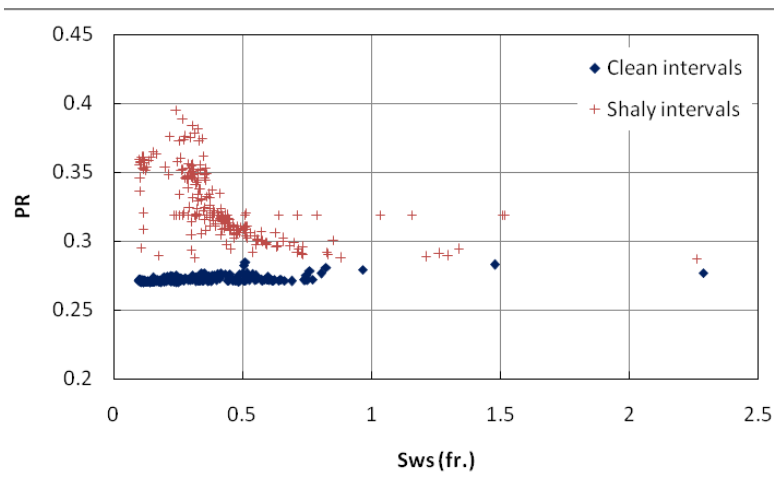

Figure 7. A. Water saturation versus Poisson's ration for Ghadamas Basin reservoir rock

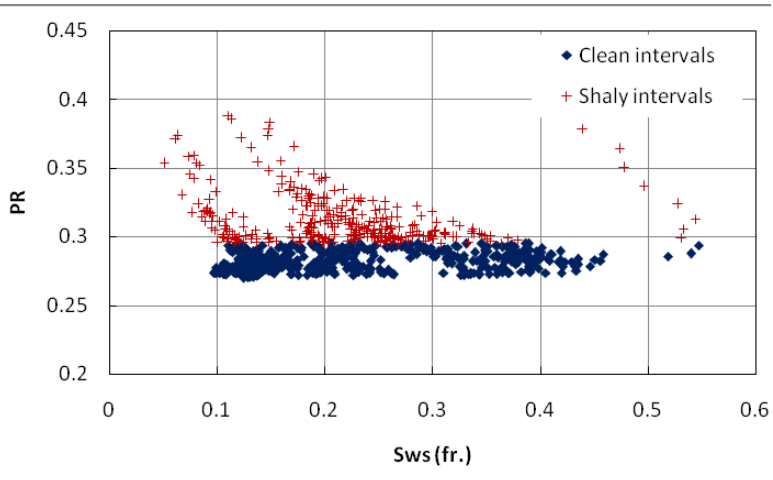

Figure 6. Water saturation versus Poisson's ration for Murzuq Basin reservoir rock

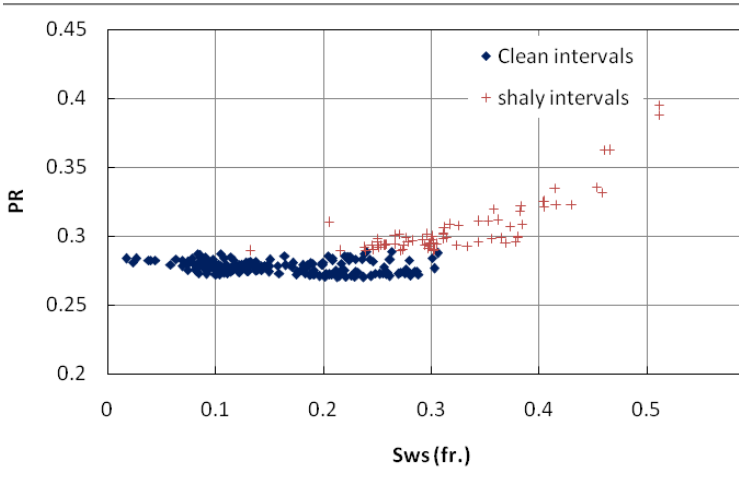

Figure 7. B. water saturation versus Poisson's ration for Ghadamas Basin reservoir rock (Gas producer) 
Poisson's ratio and Young's modulus are two of many elastic moduli and are related through the material constitutive relations (Cho and Perez, 2014). High deep resistivity values through the depths are indicating to reservoir rock if it is a less porous and /or pores contain hydrocarbon. However, the PR is not one the dynamic elastic is important for petrophysicists and have recently begun using well log derived rock properties as a proxy for rock 'brittleness' or 'ductility' (Rickman et al, 2008). Therefore, through this work relate between elastic properties (PR) which reveal changing of rock coherent as resistivity manner, and involve degree of water saturation occupied pore spaces.

Figures 8, 9 and 10 show 2D crossplots, while Figures 11, 12, 13 and 14 show continue contribuation between these properties over depth. It is clearly PR have stable range between values 0.27 and 0.28 with an increase of the deep resistivity (coherent rock), and the same phenomena occurred with the water saturation pattern. Variety of PR occurred at shaly depths with range values over 0.30 against low values of the deep resistivity and the water saturation. It noticeable observed high values of PR not related to high degrees of water saturation. Table (1) present a range values of these main properties for studied reservoirs.

Table 1. Summarized range values between physical and elastic property of studied reservoirs

\begin{tabular}{llll}
\hline Rock type & PR & Rd (Ohm.m) & Sw \% \\
\hline Clean Sandstone & $0.25-0.30$ & $10-<1000$ & $0-<50$ \\
\hline Shaly sand & $0.30-0.40$ & $<10-<50$ & $10-70$ \\
\hline
\end{tabular}

Consequintly, the fluid contain pores of rock (high content water) doesn't have major affect on the PR as resistivity parameter. While porosity variations lead to areas that are more susceptible to failure and ultimately reduce the rock's overall strength. Furthermore, an increase in porosity will enhance the rock's ability to fail under stress. According to that, Perez (2013) illustrates an increase in quartz content ( clean depths) will lower the Poisson's ratio and Rickman et al., (2008) considered brittle rocks whoms have low PR. The studied reservoirs ranged from brittle to ductle rocks.

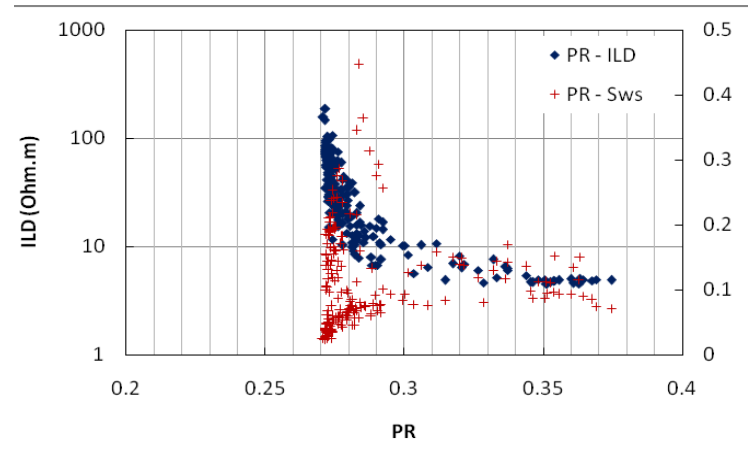

Figure 8. Poisson's ratio versus resistivity and water saturation of studied reservoir, SE Sirt Basin, Libya

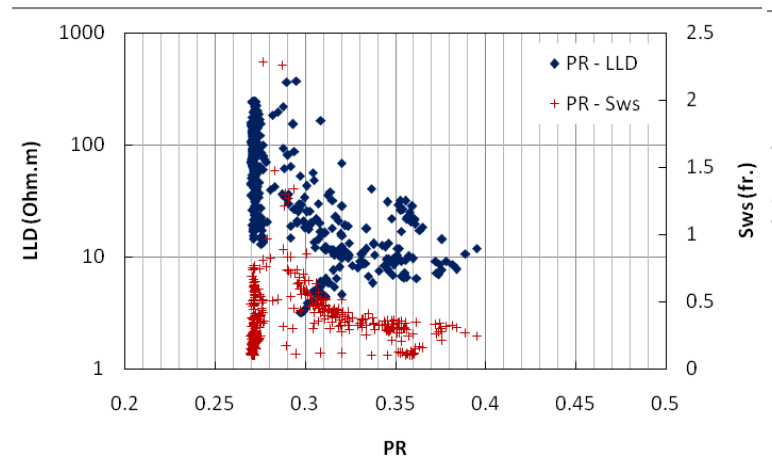

Figure 10. A. Poisson's ratio versus resistivity and water saturation studied reservoir, Ghadamas Basin, Libya

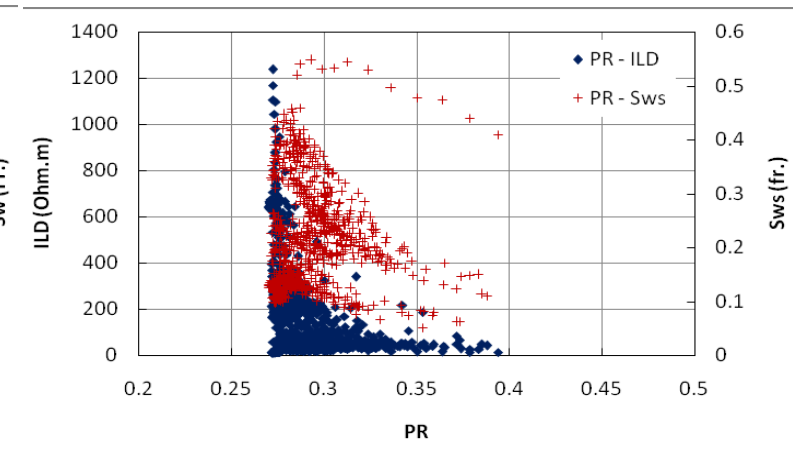

Figure 9. Poisson's ratio versus resistivity and water saturation studied reservoir, Murzuq Basin, Libya

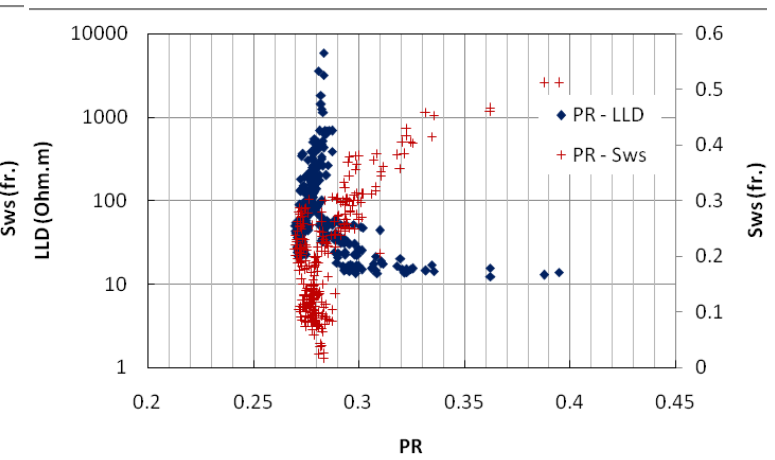

Figure 10. B. Poisson's ratio versus resistivity and water saturation studied reservoir, Ghadamas Basin, Libya (Gas producer) 


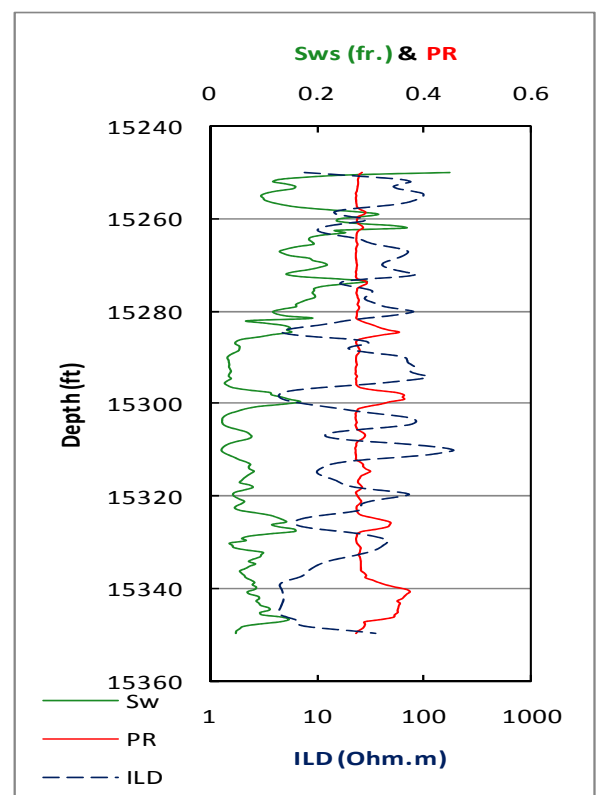

Figure 11. Water saturation, Resistivity and Poisson's ratio studied reservoir, SE Sirt Basin, Libya

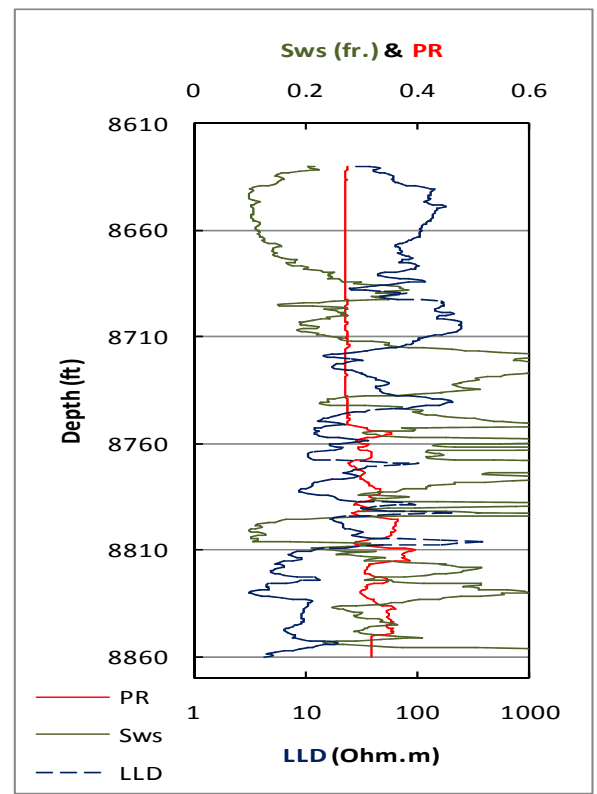

Figure 13. Water saturation, Resistivity and Poisson's ratio studied reservoir, Ghadamas Basin, Libya

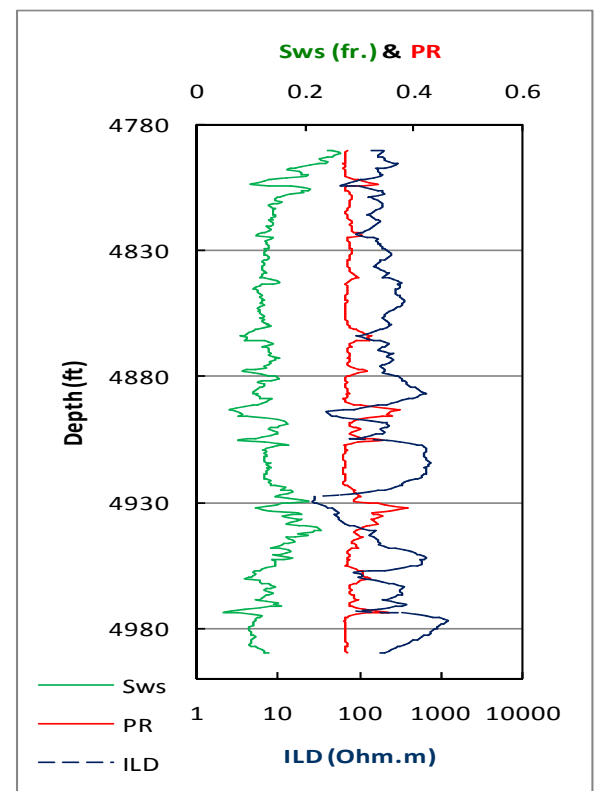

Figure 12. Water saturation, Resistivity and Poisson's ratio studied reservoir, Murzuq Basin, Libya

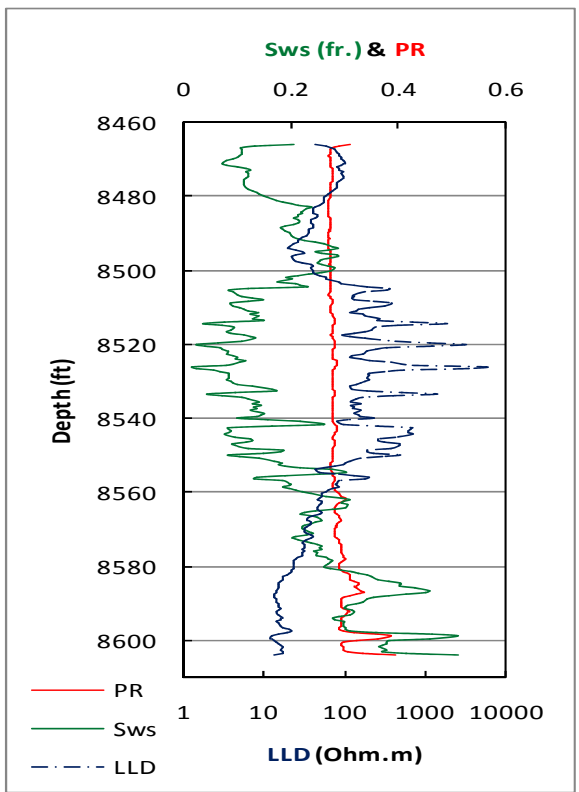

Figure 14. Water saturation, Resistivity and Poisson's ratio studied reservoir, Ghadamas Basin, Libya (Gas producer well)

\section{Conclusion}

Through this paper cross relation were presented and shown, easier and quick approach to predicate or estimate PR and define weakness depth, which define stability of borehole and/or reservoir coherent. Majority of this approach is easier applicable and economic procedure. However, low resistivity measurements confirm low water saturation content, which is common in producer reservoir have stable Poisson's Ratio between two limit values 0.27 and 0.28 , while high reading of PR excess 0.28 up to 0.40 at high water saturation content with 
stable deep resistivity measurements (about $10 \mathrm{Ohm} . \mathrm{m}$ ) or high deep resistivity (over $100 \mathrm{Ohm} . \mathrm{m}$ ). It clearly present that fluid content occupied the pore space of shaly reservoir (Hydrocarbon; oil and/or gas or water) not responsible on variety of PR. Whereas the shale content is the only reason cause effect of PR values.

\section{References}

Asquith, G., \& Krygowski, D. (2004). Basic Well Log Analysis: AAPG Methods in Exploration, 16, 31-35.

Crain, E. R. (2000). PETROPHYSICAL Handbook: ELASTIC PROPERTIES OF ROCKS.

Crain, E. R., \& Holgate, D. (2014). Digital Log Data to Mechanical Rock Properties for Stimulation Design. Geoconvention 2014: Focus.

Dvorkin, J., Moos, D., Packwood, J., \& Nur, A. (2001). Identifying Patchy Saturation from Well Logs, Department of Geophysics: Stanford University, Short Note.

Dvorkin, J. (2006). Can gas sand have a large Poisson's ratio? SEG, Stanford University and Rock Solid Images.

Hilfan, K., \& Zuhar, Z. T. H. (2007). Joint inversion of porosity for establishing velocity - Conductivity relationship by using Levenberg-Marquardt and Singular value decomposition: International conference on intelligent and advance systems.

Perez, M. (2013). Seismic modeling of unconventional reservoirs. Focus Article CSEG Recorder.

Rickman, R., Mullen, M., Petre, E., Grieser, B., \& Kundert, D. (2008). A practical use of shale petrophysics for stimulation design optimization: All shale plays are not clones of the Barnett Shale: SPE annual technical conference and exhibition, Denver, Colorado, SPE 115258.

Stenson, J. D., \& Sharma, M. M. (1989). A Petrophysical Model for Shaly Sands. SPE Annual Technical Conference and Exhibition, 8-11 October 1989, San Antonio, Texas: Publisher Society of Petroleum Engineers Language English Document ID 19574-MSDOI. 10.2118/19574-MS.

Ursin, B., \& Carcione, J. M. (2007). Seismic-Velocity/Electrical-Conductivity Relations. EGM 2007 International Workshop Innovation in EM, Grav and Mag Methods: A new Perspective for Exploration Capri, Italy.

\section{Copyrights}

Copyright for this article is retained by the author(s), with first publication rights granted to the journal.

This is an open-access article distributed under the terms and conditions of the Creative Commons Attribution license (http://creativecommons.org/licenses/by/3.0/). 